\title{
Bahasa Sunda Di Jatinegara Kaum Dan Pemukiman Keturunan Pangeran Achmad Djaketra
}

\section{Wati Kurniawati}

Keywords: linguistic, sundanese, jakarta, ethnoarchaeology, language

\section{How to Cite:}

Kurniawati, W. Bahasa Sunda Di Jatinegara Kaum Dan Pemukiman Keturunan Pangeran Achmad Djaketra. Berkala Arkeologi, 16(1), 49-57. https://doi.org/10.30883/jba.v16i1.746

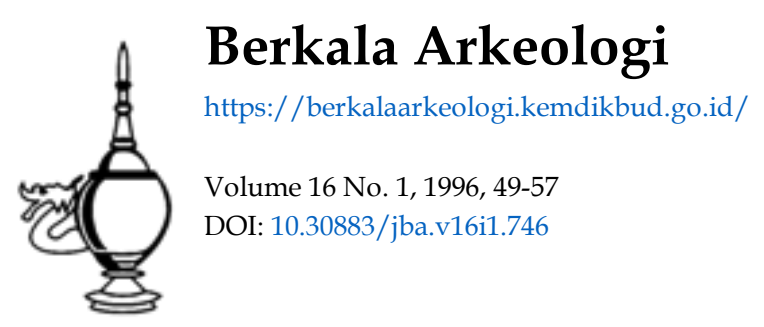

\section{cc) (7) (2)}

This work is licensed under a Creative Commons Attribution-NonCommercial-ShareAlike 4.0 International License. 
Wati Kurniawati

(Staf Bidang Bahasa Indonesia dan Daerah

Pusat Pembinaan dan Pengembangan Bahasa)

\section{Pendahuluan}

- Jakarta adalah kota yang multietnis. Penduduknya sebagian besar terdiri dari kelompok etnis Sunda, Jawa, Betawi, dan Cina (Muhadjir, dkk,1986:17): Masyarakat heterogen ini tentu mempunyai latar belakang bahasa ibu yang berbeda-beda dan memungkinkan timbulnya variasi bahasa menurut perbedaan daerah asal. Di kota Jakarta yang penduduknya berbahasa Melayu dialek Betawi ada sekelmpok penduduk yang berbahasa Sunda. Penduduk yang sehariharinya bertutur dalam bahasa Sunda ini bermukim di RW 03 Jatinegara Kaum.

Pada tahun 1619 penduduk Jatinegara Kaum berasal dari Banten yang bertutur dalam Bahasa Sunda (Sudjito, dkk., 1975:17) Sekarang bahasa Sunda di RW 03 Jatinegara Kaum hanya dituturkan oleh penduduk yang mengaku keturunan Pangeran Achmad Djakerta dan Pangeran Sageri.

\section{Tinjauan Sejarah}

Jatinegara Kaum pada zaman penjajahan Belanda pernah menjadi tempat pengaturan Pangeran Achmad Djakerta dalam menentang penjajahan Belanda (1619-1684). Beliau dalam menentang penjajahaan Belanda bekerja sama dengan Pangeran Sageri, Pangeran Sangiang, dan perigikutnya (Sudjito, dkk., 1975:6-7).

Untuk mengetahui asal-usul pemakai bahasa Sunda di Jatinegara Kaum kita perlu mengetahui sejarah singkat Pangeran Achmad Djakerta menurut pengakuan warga Jatinegara Kaum dan sumber sejarah yang ada hubungannya. Menurut sesepuh "Rukun warga Pangeran Achmad Djakerta Jatinegara Kaum" dan Djajanegara (1982:1-2) pada tahun 1525 Banten dan Cirebon ada dibawah kekuasaan Sunan Gunung Jati yang dikenal dengan nama Fatahillah. Kemudian, tahun 1527 beliau berhasil merebut Sunda Kelapa, bandar kerajaan Pajajaran dari tangan Portugis. Setelah berhasil menghancurkan Portugis, Fatahillah mengadakan upacara tasyakuran pada tanggal 
22 Juni 1527 di Sunda Kelapa sebagai rasa syukur kepada Allah SWT. Fatahillah mengganti nama Sunda Kelapa menjadi Jayakarta yang berarti "kota kemenangan" dan menganugerahkan gelar "Pangeran Jayakarta" bagi penguasa negeri itu. Fatahillah sebagai pahlawan Jayakarta yang pertama mengangkat dan menobatkan putera sulungnya, Maulana Hasanuddin sebagai penguasa pertama di Banten termasuk Jayakarta di bawah kekuasaannya sampai tahun 1570. Pada tahun 1570 Maulana Hasanuddin mengangkat putera dan putrinya, yaitu Maulana Yusuf sebagai Sultan Banten yang kedua dan Ratu Pembayun bersama suaminya, Ratu Bagus Angke (Tubagus Angke) sebagai Pangeran Jayakarta yang pertama dengan status raja bawahan dari Kesultanan Banten.

Pada tahun 1596 orang-orang Belerrdă datang ke Jayakarta di bawah pimpinan Cornelis de Houtman (Sudjito, dkk.,1975:1). Saat itu Tubagus Angke sebagai Raja Jaketra sudah lanjut usia. Pemerintahan pun diserahkan kepada kepada putranya, Pangeran Sungerasa Djajawikarta atau Kawis Adimerta yang dikenal dengan nama Pangeran Aria Tengah atau Pangeran Katengahan. Beliau sebagai Pangeran Jayakarta yang kedua berkedudukan di kota Inten dekat Pasar Ikan, Jakarta Kota (Djajanegara,1982:2). Sejak tahun 1596 Pangeran Sungerasa Djajawikarta adalah raja bawahan kesultanan Banten (Barnas, dkk., 1972:8).

Nama Pangeran Sungerasa Djayawikarta ini memang berbeda dengan yang terdapat dalam Babad Banten dan Babad Cirebon. Dalam Babad Banten dijumpai nama Pangeran Jakerta, Jayawikarta, dan Kawis Adimerta; dalam babad Cirebon hanya disebutkan Pangeran Jaketra. Sumber-sumber asing menyebutnya Conick, Regent van Jacattra, atau King of Jacatra, nama ini diberikan kepada Djajawikarta atau Pangeran Djakarta Wijayakrama (Sudjito, dkk.,1975:2). Menurut Djajadiningrat (1983:185), perbedaan nama ini tidaklah mengherankan karena Pangeran Sungerasa Djajawikarta mempunyai nama lebih dari satu dan hal ini di Indonesia merupakan sesuatu yang biasa.

Kehadiran orang-orang Belanda di Jayakarta sering menimbulkan perselisihan dengan Pangeran Sungerasa Djajawikarta. Apalagi setelah diadakan perjanjian dagang VOC (Vereenigde Oost Indhische Compagnie) tahun 1610 yang ditandatangangi oleh L. Hermite. Isi perjanjian dagang itu banyak merugikan Pangeran Sungerasa Djajawikarta. Misalnya, izin yang diberikannya kepada VOC untuk mendirikan bangunan gudang ternyata oleh VOC dipakai juga untuk mendirikan benteng pertahanan (Djajanegara, 1982:2).

Kedatangan Jan Pietetszoon Coen sebagai Presiden Kantor Dagang Banten dan Jayakarta yang ingin menjajah Jayakarta menja- 
dikan perselisihan yang ada semakin meruncing dan menimbulkan bentrokan fisik. Kemudian, tahun 1618 benteng Belanda dikepung tentara Jayakarta yang dibantu Inggris. J.P. Coen lari ke Maluku mancari bala bantuan. Benteng Belanda dipercayakan kepada Pieter van de Broeck dengan harapan mampu bertahan atau berunding apabila keadaan terjepit. Karena terdesak, Broeck mengadakan perundingan dengan Pangeran Sungerasa Djajawikarta. Pergaulan Broeck dengan Pangeran Sungerasa Djajawikarta tidak berlangsung lama karena Coen datang dengan bala bantuannya. Pada tanggal 30 Mei 1619 VOC membumihanguskan kota Jayakarta yang telah direbut Belanda namanya diubah menjadi Batavia. Menurut Barnas dkk (1972:9-12), pada tanggal 15 Februari 1619 datang utusan dari Banten ke Jayakarta agar Pangeran Sungerasa Djajawikarta yang bekerja sama dengan Inggris menghadap Sultan Banten. Kepergian Pangeran Sungerasa Djajawikarta ke Banten mengakibatkan kota Jayakarta dibumihanguskan oleh Belanda. Belanda menganggap pemerintahan di Jayakarta sudah tidak ada lagi yang memerintah tidak mampu lagi menemukan jejak Pangeran Achmad Djaketra bersama pengikutnya dan menyatakan bahwa Pangeran Achmad Djaketra telah mati di dalam sumur yang telah dihujani peluru. Namun, hakikatnya tidak demikian. Berkat pertolongan Allah SWT, Pangeran Achmad Djaketra bersama pengikutnya berhasil menghilangkan jejaknya (Barnas, dkk., 1972:13-14).

Pangeran Achmad Djaketra dalam perang terbuka mengalami kekalahan, tetapi dalam bentuk perang mental tetap menang. Basis pertahanannya pun pindah ke arah timur Jakarta, letaknya di seberang Kali Sunter dan masih merupakan hutan belukar yang ditumbuhi pohon jati (Barnas, dkk., 1975:14).

Djajanegara (1978:1) mengemukakan bahwa pada tahun 1619 Pangeran Achmad Djaketra meresmikan tempat di seberang kali sunter dan diberi nama Jatinegara yang berarti "pemerintahan yang sejati" dengan luas wilayah 1.200 hektar. Menurut "Laporan Pembinaan Wilayah Kelurahan Jatinegara Kaum Tahun 1986/1987" (1987:3), nama Jatinegara yang mempunyai nilai historis sekarang dikenal dengan nama Jatinegara Kaum dengan luas wilayah kurang lebih 123.43 hektar. Barnas dkk. (1972:20) mengemukakan bahwa nama Jatinegara yang dikenal orang setelah zaman pendudukan Jepang sampai sekarang ialah daerah bekas Meester Coenelis. Menurut sesepuh "Rukun Warga Pangeran Achmad Djaketra Jatinegara Kaum", di Jatinegara Kaum inilah Pangeran Achmad Djaketra menyusun kekuatan dan melakukan perang gerilya serta mengadakan serangan-serangan balasan ke kota Jayakarta, tempat 
pertahanan Kompeni Belanda. Setelah Pangeran Achmad Djaketra meresmikan Jatinegara, banyak keturunan dari Sultan Banten datang berangsur-angsur ke Jatinegara Kaum. Tahun 1620 didirikanlah sebuah masjid yang sampai sekarang dipelihara dengan baik oleh keturunannya dan diberi nama "Assalafiyah" yang berarti "tertua". Angka tahun pendiriannya dicantumkan pada dinding masjid bagian selatan.

Menurut Barnas dkk. (1972:16-17), pada tahun 1628 terjadi penyerangan yang dilakukan oleh pasukan Mataram ke kota Jayakarta yang dikuasasi Belanda. Sebagian kecil pasukan Mataram ada yang tidak kembali ke Mataram dan menyingkir ke sebelah timur Jatinegara Kaum, yaitu "Kampung Jawa", sejak berakhirnya peperangan antara Mataram dan Belanda pada tahun 1629 Pangeran Achmad Djaketra beserta pengikutnya mengisolir daerah Jatinegara Kaum terhadap pengaruh dari luar, yakni Belanda, sehubungan jejaknya telah hilang dari pandangan Belanda.

Pangeran Achmad Djaketra selaku pemimpin negara dan agama serta pewaris perjuangan Fatahillah yang didasarkan semangat perjuangan Islam adalah pendorong baginya untuk tetap berjihad $f i$ sabilillah. Demi kepentingan itu beliau mengajarkan ajaran Islam kepada keturunannya dan pengikutnya dengan tujuan agar semangat perjuangannya itu tetap diwarisi. Sebelum Pangeran Achmad Djaketra wafat, beliau berpesan agar anak cucu dan pengikutnya merahasiakan tempat dan keadaan beliau kepada siapa saja selama bangsa penjajah masih ada di Indonesia dan dilarang membunyikan "goong" demi keselamatan keturunannya. Sejak itu dan sampai sekarang wasiatnya tetap dipegang teguh oleh keturunannya di Jatinegara Kaum (Djajanegara, 1982:5).

Pada tahun 1640 Pangeran Achmad Djaketra wafat dengan mewariskan beberapa barang pusaka kepada keturunannya, yaitu berupa kain debus, tasbih besar, sepasang tombak yang diberi nama Biring Lanang dan Biring Galih, golok, dan masjid Assalafiyah (Sudjito, dkk., 1975:9).

Nasib Pangeran Jayakarta setelah kalah perang ada beberapa versi. Menurut Djajadiningrat (1983:184), Broeck mengatakan bahwa Pangeran Jayakarta dengan istri dan anaknya yang tertua menyingkir ke pedalaman dan mencari nafkah untuk hidupnya sebagai nelayan di lautan; Campius menceritakan bahwa Pangeran Jaketra yang diusir hidup sebagai nelayan yang melarat; Coen mengemukakan bahwa Pangeran Djaketra dan saudara-saudaranya, tumenggung bersamasama 50 orang lainnya dikirimkan ke pegunungan di Udik Tanahara, tempat mereka diamankan. menurut Tjandrasasmita, ketika sedang 
perang melawan kompeni Belanda, pangeran Jayakarta dibawa oleh utusan Sultan Banten. Hal ini dihubungkan dengan ditemukannya makam Pangeran Joyowikarto alias Pangeran Aria Tengah di Desa Kenari wilayah Serang. Makam ini diduga sebagai makam Sungerasa Djajawikarta atau Pangeran Jayakarta Wijayakrama. Sementara di Jatinegara Kaum hingga sekarang tetap diakui bahwa makam Pangeran Jayakarta yang nisannya tertulis Pangeran Achmad Djaketra adalah putra Pangeran Jayakarta Wijayakrama.

Menurut keluarga besar Pangeran Achmad Djaketra di Jatinegara Kaum, terlepas dari pandangan atau penafsiran umum, yang dimaksud dengan Pangeran Jayakarta adalah satu-satunya Pangeran Achmad Djaketra, beliaulah sebagai Pangeran Jayakarta terakhir yang dikenal masyarakat Jakarta.

Sepeninggal Pangeran Achmad Djaketra perjuangan dilanjutkan oleh anak cucu beserta pengikutnya. Pangeran Sangiang, putra Pangeran Senopati Ingalaga di Banten dan Pangeran Sageri, putra Abdul Fathi Abdul Fatah (Sultan Agung Tirtayasa) meneruskan perjuangan Pangeran Achmad Djaketra di Jatinegara Kaum, masingmasing pada tahun 1660 dan tahun 1682 (Barnas, dkk., 1972:19).

Sesepuh "Rukun Warga Pangeran Achmad Djaketra Jatinegara Kaum" mengemukakan bahwa makam Pangeran Sangiang ada di Jatinegara Kaum dan makam Pangeran Sageri ada di sebelah barat masjid Asslafiyah dekat makam Pangeran Achmad Djaketra, Pangeran Lahud, Pangeran Surya, dan Pangeran Abdul Fatah.

Makam Pangeran Surya yang semula di Kramat Tangkil dipindahkan ke pemakaman di masjid Jami' Asslafiyah pada tanggal 26 Juni 1979 karena tanah wakaf pemakaman kaum muslimin Kramat Tangkil diperlukan pemerintah DKI Jaya untuk pembangunan Proyek Air Minum (PAM). ketika makam itu digali sedalam kurang lebih 1,5 m. panitia tidak menemukan tulang kerangka Pangeran Surya. Sebagai syarat pemindahan, panitia memutuskan untuk memindahkan sebagian tanah merah galian dari makam Pangeran Surya ke tempat pemakaman di.lingkungan masjid Jami' Assalafiyah. Akan tetapi, pada tanggal 28 Agustus 1979 R. Utin Suryatin bin R. Hamim dan keluarga keturunan Pangeran Surya kembali melanjutkan penggalian makam Pangeran Surya di Kramat Tangkil kurang lebih sedalam 0,75 meter lagi dan ditemukan kerangka Pangeran Surya, selanjutnya dipindahkan ke tempat pemakaman kaum muslimin di Kebun Wuruk.

\section{Wilayah, Penduduk, dan Bahasa.}

Sebelum tahun 1950 wilayah Jatinegara Kaum merupakan daerah terisolir. Sesuai dengan pesan Pangeran Achmad Djaketra, 
untuk menjaga kerahasiaannya, dalam perkawinanan, keturunannya dianjurkan menikah antara sepupu, tidak boleh dengan "orang luar" Dalam kegiatan sehari-hari mereka pun berkomunikasi dalam bahasa Sunda.

Sekarang Jatinegara Kaum merupakan salah satu kelurahan di Kecamatan Pulo Gadung yang terletak di bagian timur, wilayah kota Jakarta Timur. Kelurahan Jatinegara Kaum dibagi menjadi 6 RW dengan 79 RT. Di antara keenam RW hanya RW 03 yang penduduknya memakai bahasa Sunda dalam kehidupannya sehariharinya, kecuali dengan pendatang yang tidak berbahasa Sunda mereka memakai bahasa Indonesia. Wilayah RW 03 letaknya dikelilingi oleh wilayah yang penduduknya berkomunikasi dengan bahasa Melayu dialek Betawi. Berdasarkan "Laporan Pembinaan Wilayah Kelurahan Jatinegara Kaum Tahun 1986/1987", jumlah penduduk RW 03 ada 2.847 jiwa tidak seluruhnya pemakai bahasa Sunda. Pemakai bahasa Sunda adalah penduduk yang berasal dari keturunan Pangeran Achmad Djaketra dan Pangeran Sageri memakai gelar "Raden" di depan namanya. Mereka bertutur dalam bahasa Sunda dan bertempat tinggal di RW 03 Jatinegara Kaum. Selain pemakai bahasa Sunda, banyak juga pendatang yang bertempat tinggal di RW 03 Jatinegara Kaum. Pemakai bahasa Sunda di Jatinegara Kaum (disingkat BSJK) yang sekarang ada kurang lebih 900 jiwa, semuanya beragama Islam. Jumlah penduduk yang tergolong pendatang kurang lebih ada 1.947 jiwa.

Pemakai BJSK sekarang semakin berkurang karena mereka beranggapan bahwa bahasa Sunda yang dipakainya "kasar". Selain itu, ada beberapa faktor lain, yaitu (1) Perkawinan antara sepupu sejak tahun 1950 di lingkungan pemakai BSJK tidak lagi diharuskan oleh orang tua mereka; (2) Pemakai BSJK banyak menjual tanahnya sehingga mereka pindah ke tempat lain dan pendatang banyak yang menetap di wilayah ini; (3) Jumlah pemakai BSJK sebelum tahun 1950 kurang lebih 100\% dan sekarang kurang lebih 35\%; (4) Generasi muda usia sekolah dasar tidak lagi memakai BSJK dalam komunikasinya sehari-hari, baik dengan orang tuanya maupun teman sebayanya; (5) Orang tua tidak lagi membiasakan atau mengajarkan anak-anaknya untuk bisa berbahasa Sunda karena bahasa Sunda yang dipakainya "kasar" dan mereka merasa malu kalau anaknya berbahasa Sunda "kasar"

Faktor-faktor tersebut di atas tentu dapat mempengaruhi bahasa yang dipakai oleh sekelompok kecil pemakai bahasa Sunda di Jatinegara Kaum yang ada di lingkungan bahasa Melayu dialek Betawi 


\section{Penutup}

Pemakai bahasa Sunda di Jatinegara Kaum berdasarkan tinjauan sejarah, yaitu keturunan Pangeran Achmad Djaketra dan Pangeran Sugeri yang memakai gelar "Raden". Penutur BSJK sekarang semakin berkurang karena faktor sosial, geografis bahasa dan faktor kedudukan bahasa masing-masing itu.

\section{Kepustakaan}

Anonim,1985, Data Potensi Wilayah Tahun 1984/1985, Jakarta Rukun Warga 03 Jatinegara Kaum, tidak diterbitkan.

Anonim,1987, Laporan Pembinaan Wilayah Kelurahan Jatinegara Kaum Tahun 1986/1987. Jakarta:Pemerintah Daerah Khusus Ibukota Jakarta:tidak diterbitkan.

Ayatrohaedi,1979. Dialektologi, Sebuah Pengantar. Jakarta:Pusat Pembinaan dan Pengembangan Bahasa.

1982, Bentuk Hormat dalam Bahasa Sunda, dalam Pelangi Bahasa, Jakarta:PT Bhratara.

Barnas, R. Tatang Effendi, dkk,1972, Peranan Perjuangan Pangeran Achmad Djaketra dan Pengaruhnya terhadap Pengembangan Islam di Jakarta, Jakarta:tidak diterbitkan.

Djajadiningrat, Hoesin,1983, Tinjauan Kritis tentang Sejarah Banten, Jakarta:Djambatan.

Djajanegara, R.Sy.,1978, Jatinegara Daerah Historis, Jakarta tidak diterbitkan.

1982, Sejarah Perjuangan Pahlawan Jayakarta, Jakarta.tidak diterbitkan.

Djajawiguna, Buldan R.I.,1978, Babaran Undak-Usuk Basa Bandung:Lembaga Basa Jeung Sastra Sunda. 
Koentjaraningrat, (ed), 1984, Manusia dan Kebudayaan di Indonesia Jakarta:Djambatan.

Metode-metode Penelitian Masyarakat. Jakarta:Gramedia.

Kurniawati, Wati,1988, Pemakaian Kata Sapaan di RW 03 Jatinegara Kaum. Skripsi Sarjana. Jakarta:Fakultas Sastra Universitas Indonesia.

Muhadjir, dkk,1986, Peta Seni Budaya Betawi. Jakarta:Dinas Kebudayaan DKI Jakarta.

Nababan, P.W.J. 1984. Sosiolingistik Suatu Pengantar. Jakarta:Gramedia.

Tjandrasasmita, Uka,1977, Pasang Surut Perjuangan Pangeran Jakarta Wijayakrama Jakarta:Pemerintah DKI Jakarta Dinas Museum dan Sejarah.

Tjandrasasmita, Uka (ed),1976. Sejarah Nasional Indonesia III. Jakarta:Departemen Pendidikan dan kebudayaan 
SYARIF HIOAYATULLAH

(SUNAN GUNUNG JATI)

MAULANA HASANUDDIN

(PANEMBAHAN SURASOWAN)

berpura

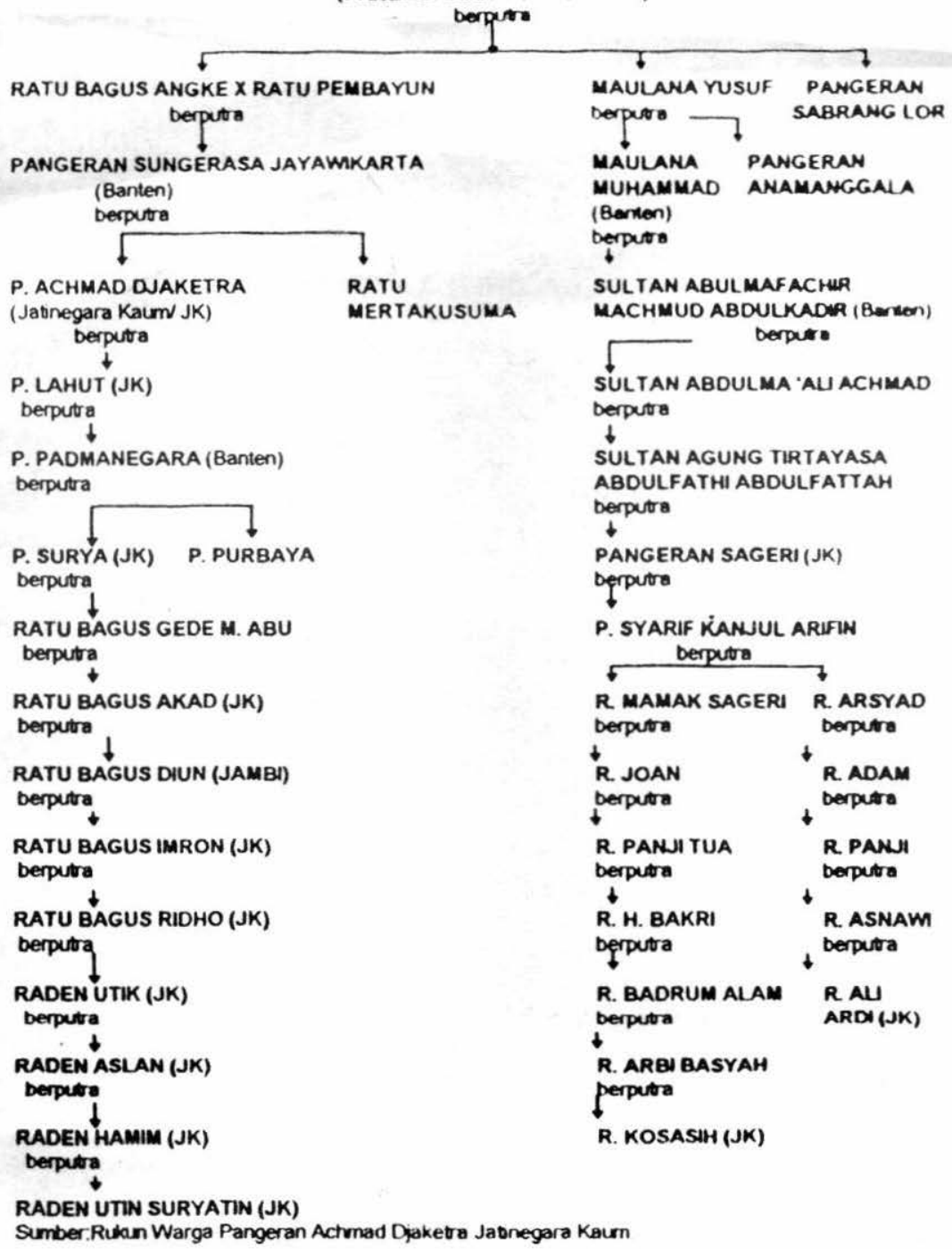

